\title{
Immunoglobulin G to Albumin Ratio Measurement
}

National Cancer Institute

\section{Source}

National Cancer Institute. Immunoglobulin G to Albumin Ratio Measurement. NCI

Thesaurus. Code C147372.

The determination of the ratio of IgG compared to albumin present in a sample. The measurement may be expressed as a ratio or percentage. 